\title{
Essential Role of IL-6 Signaling Pathway in Keloid Pathogenesis
}

\author{
Mohammad Ghazizadeh
}

Department of Molecular Pathology, Institute of Gerontology, Postgraduate School of Medicine, Nippon Medical School

\begin{abstract}
Cytokines are pleiotropic substances that are known to participate in inflammatory and immune responses as well as cell differentiation and proliferation. Interleukin-6 (IL-6) is a key cytokine with pro-inflammatory function. Wound healing is a complex cascade of physiologic events comprising inflammation, proliferation and remodeling, and proceeds with the integrated actions of different cells, cytokines, and the extracellular matrix. Aberrant wound healing results in keloid formation which causes disfigured appearance, discomfort, psychological stress, and patient frustration.

In this review, the role of IL-6 signaling pathway in the pathogenesis of keloid is assessed and its potential as a therapeutic target is addressed. The existing data suggest that IL-6 mediated inflammation is a key player and may be considered as a common causative factor for development of keloid. Furthermore, in a recent comprehensive study, we confirmed the functional role of IL-6 signaling in keloid pathogenesis.

Accordingly, inhibitory strategies of IL-6 signaling pathway by targeting the IL-6 receptors, its downstream effecters, or other molecules influencing this pathway appear to have considerable potential as new therapeutic or preventive challenges for keloid. Hopefully, several IL-6 blocking agents including a humanized antibody to IL-6 receptor have been developed and successfully used in clinical trials of inflammatory diseases. It is likely that these agents may prove worthy in the treatment or prevention of keloid as well. Future in-depth exploration of such challenges will shed light on their efficacy and safety for clinical application in keloid.
\end{abstract}

(J Nippon Med Sch 2007; 74: 11-22)

Key words: wound healing, keloid, interleukin-6, receptors, inhibitors, anit-interleukin-6 antibody, interleukin-6 signaling pathway

\section{Introduction}

Wound healing is a complex cascade of physiologic events comprising inflammation, proliferation and remodeling, and proceeds with the integrated actions of different cell types, cytokines, and the extracellular matrix. Aberrant wound healing results in keloid formation, causing disfigured appearance, discomfort, psychological stress, and patient frustration. Keloid develops after dermal injury and classically occurs on certain parts of the body, specifically, on the shoulder, anterior chest wall, and earlobes (Fig. 1). Keloid is characterized by

Correspondence to M. Ghazizadeh, MD, Department of Molecular Pathology, Institute of Gerontology, Postgraduate

School of Medicine, Nippon Medical School, 1-396 Kosugi-cho, Nakahara-ku, Kawasaki, Kanagawa 211-8533, Japan

E-mail: ciem@nms.ac.jp

Journal Website (http://www.nms.ac.jp/jnms/) 


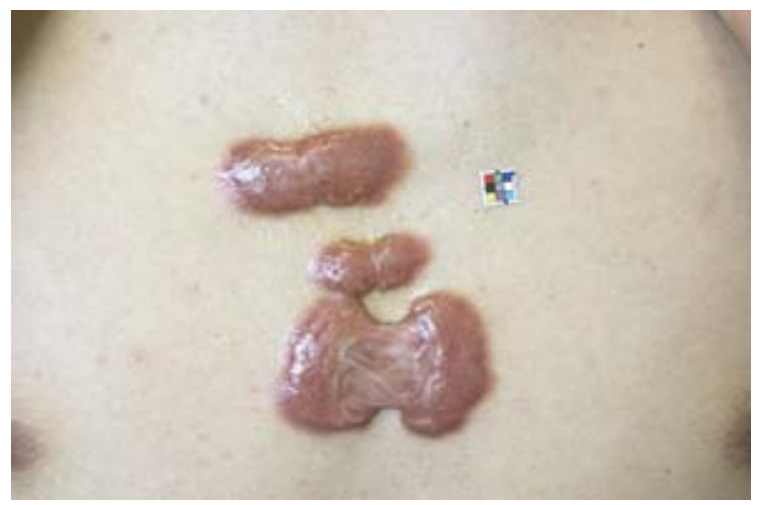

Fig. 1 Clinical appearance of keloid on anterior chest wall. The scars appear to have a central constriction part and expand from both lateral sides, probably due to skin tension. (Courtesy of Dr. Mamiko Tosa, Department of Plastic Surgery, Nippon Medical School).

excessive collagen synthesis and fibroblastic cell proliferation $^{1.2}$ (Fig. 2). It is unique to humans and has not yet been seen or produced in rodents, thus encountering the problem of the lack of experimental animal models for in vivo studies. Many factors such as skin tension, wound infection, racial difference, genetic predisposition, immune dysfunction, and sebaceous gland density have been implicated in the etiology of keloid ${ }^{3.4}$. Most of these factors involve inflammatory and immune responses.

Cytokines, particularly interleukin-6 (IL-6), play pivotal roles in controlling the immune system and communication among cells of mammals. As intercellular mediators, they regulate differentiation, growth, survival, and effecter functions of cells. They are secreted mainly by lymphocytes and macrophages, but other cell types including fibroblasts and endothelial cells also secret them. Cytokines act by altering the function of target cells in a paracrine or autocrine fashion. Several common structural and functional characteristics exist among cytokines including that they are: glycosylated polypeptides, biologically active at very low concentrations, pleiotropic i.e. having multiple effects, bind to receptors on the cell surface, and exert additive, synergistic or antagonistic effects? The overall outcome of event will thus be determined by various interactions among these effects.

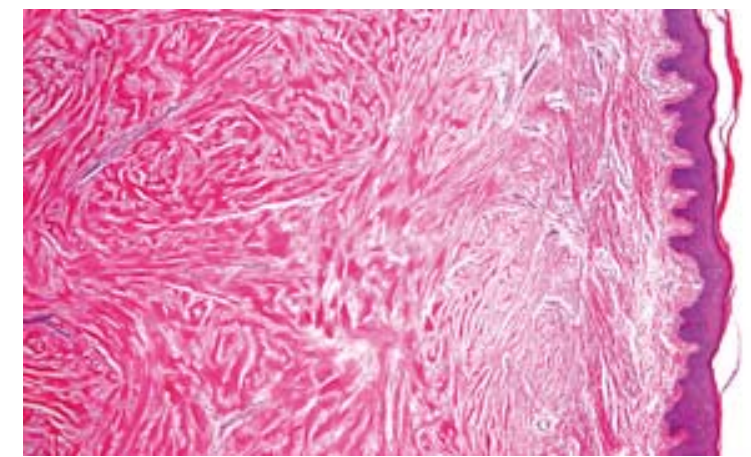

Fig. 2 Histological feature of keloid tissue stained with hematoxylin and eosin showing abundant disordered collagen bundles and fibroblastic cell proliferation. Original magnification $\times 40$.

Several treatment modalities have been challenged for keloid scar including intralesional injections of glucocorticosteroids, surgical excision, cryotherapy and wound compression ${ }^{8}$. Intralesional injections of human interferon alpha- $2 b^{9}$; and topical applications of retinoids $^{10.11}$, or electron beam irradiation immediately after surgical removal of keloid ${ }^{12.13}$ have also been employed. In the majority of therapeutic modalities, variable results have been encountered. Therefore, alternative therapies with superior and uniform effect as well as lesser or no hazard need to be developed. For example the effects of the calcium antagonist verapamil on the IL-6 and vascular endothelial cell growth factor (VEGF) as well as cellular growth have been evaluated in primary cultures of fibroblasts derived from the central part of keloid lesions ${ }^{14}$. Compared with peripheral and non-keloid fibroblasts, central keloid fibroblasts grow faster and present an increased production of both IL-6 and VEGF. Treatment with verapamil reduces IL-6 and VEGF production in central keloid fibroblast cultures, decreases cellular proliferation and increases apoptosis, thus providing a link with the beneficial effect of calcium antagonists on keloids in vivo.

In the present article, the role of IL-6 signaling pathway in the pathogenesis of keloid is reviewed and its potential as a therapeutic target for future clinical application is addressed. 


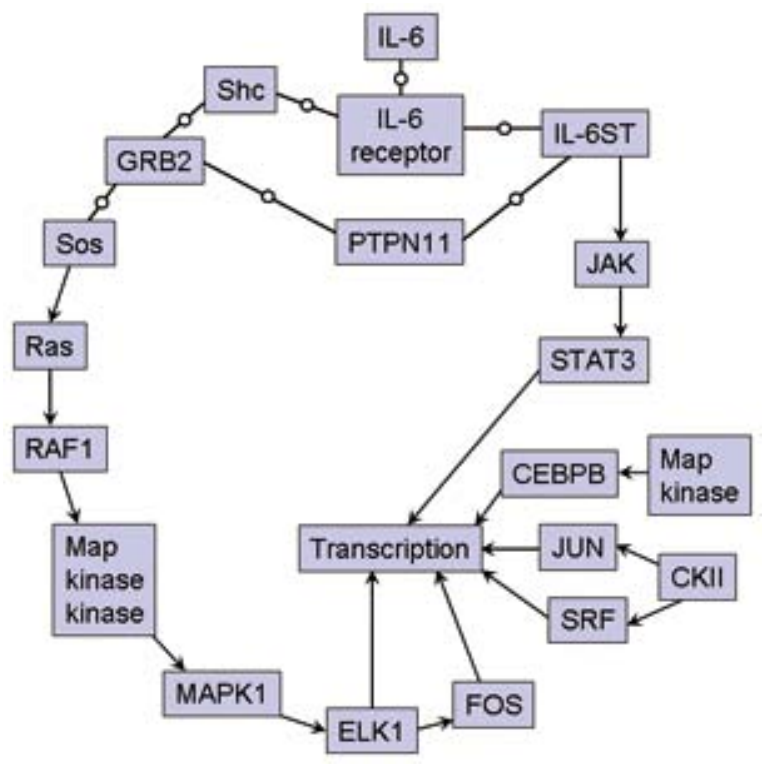

Fig. 3 IL-6 signal transduction pathway. Upregulation of IL-6 in keloid fibroblasts would result in augmentation of the downstream target genes, leading to the increased transcription of several genes including those related to the cell proliferation and matrix synthesis.

\section{IL-6 Functions}

Natural human IL-6 is a single-chain glycoprotein with a relative molecular mass of $21 \mathrm{~K}$ to $30 \mathrm{~K}$ depending on the cellular source and method of preparation $^{15,16}$. This variability in mass appears to be due to extensive post-transcriptional modification ${ }^{17}$. Higher molecular mass forms of natural IL- 6 derived from fibroblasts with a range of $45 \mathrm{~K}$ to $85 \mathrm{~K}$ has been observed ${ }^{18}$. These forms have been shown to be oligomeric complexes of post-translationally modified IL-6. The post-translational modification of IL-6 appears to have little or no effect on its biological activity, as evidenced by the identical activity of IL-6 derived from different recombinant sources with that of natural IL-6.

IL-6 is an immunoregulatory cytokine that activates a cell-surface signaling assembly composed of IL-6, IL-6 receptor alpha (IL-6R $\alpha$ ), and the shared signal transducer receptor (IL-6ST) also called glycoprotein subunit gp130 (IL-6Rß) receptor (Fig. 3). IL-6 exerts its action on target cells by binding to IL-6R $\alpha$ on cell membrane following which it interacts with gp130 in the proper geometry to facilitate transition into a high affinity signalingcompetent hexamer ${ }^{19,20}$. A soluble form of IL-6 receptor that lacks the cytoplasmic domain also exists $^{21,22}$. Binding of IL- 6 to either the membranebound or soluble form of IL-6 receptor in the presence of gp130 transmits signal into cells. This results in subsequent activation of signal transducers and activators of transcription factors such as Janus kinase (JAK)/signal transducer and activator of transcription 3 (STAT3), mitogenactivated protein kinase (MAPK)/extracellular signal-regulated kinase ( ERK ), and phosphatidylinositol 3-kinase (PI3K). The MAPK pathway activates several transcription factors including ELK1 and nuclear factor (NF)-IL-6 (CCAAT enhancer-binding protein beta; CEBPB) which promote cell proliferation and matrix synthesis. On the other hand, STAT3 also upregulates the transcription of genes encoding the suppressor of cytokine signaling 3 (SOCS3) proteins that are intracellular negative-feedback factors that inhibit the JAK/STAT3 pathway. In the presence of IL-6, serum-derived soluble IL-6 receptor (sIL-6R) has a stimulatory effect on cells expressing gp130 Therefore, the IL-6/sIL-6R complex has been regarded as the real target to be inhibited in vivo ${ }^{24}$. Serum-derived soluble gp130 (sgp130) acts as an IL-6 antagonist in the presence of serum-derived sIL-6R and IL-6, and also inhibits the biological effects of leukemia inhibitory factor (LIF), oncostatin M (OSM), and ciliary neurotrophic factor $(\mathrm{CNTF})^{23}$. The relative concentrations of sIL-6R and sgp130 and IL6 in serum may thus, in part, determine their physiological effects. The important participants in the IL-6 signaling pathway include the JAK1, JAK2 and protein-tyrosine kinase 2 (TYK2), the signal transducers and activators of transcription factor STAT1 and STAT3, the tyrosine phosphatase SHP2 [SH2 (Src homology 2) domain-containing tyrosine phosphatase] and transcription nuclear factor NFkappaB and inhibitor of NF-kappaB kinase (IKK). Furthermore, the IL-6 signaling pathway is involved in cross-talk with NF-kappaB ${ }^{25}$ and is considered as a target of NF-kappaB.

The NF-kappaB and IKK proteins regulate many 
physiological processes, including the immune responses, cell death and inflammation, and disruption of NF-kappaB or IKK functions contributes to many human diseases ${ }^{26}$. There are many mechanisms that integrate the activity of NFkappaB and IKK proteins with other cell-signaling pathways. The outcome of such events determines the consequences of NF-kappaB and IKK activation and eventually the cell fate ${ }^{26}$.

The IL-6 cytokine family is composed of IL-6, IL11, leukemia inhibitory factor, oncostatin $\mathrm{M}$, ciliary neurotrophic factor and cardiotrophin-1 (CT-1). IL-6 has pro-inflammatory function and is produced by a variety of cell types including $\mathrm{T}$ cells, $\mathrm{B}$ cells, monocytes, fibroblasts, keratinocytes, endothelial cells, and mesangial cells. Its expression is regulated by a variety of factors, including steroidal hormones, at both the transcriptional and post-transcriptional levels. IL-6 has been implicated in the pathogenesis of many diseases including rheumatoid arthritis ${ }^{27}$, multiple myeloma ${ }^{28}, \operatorname{AIDS}^{29}$, mesangial proliferative glomerulonephritis ${ }^{30}$, Castleman disease ${ }^{31}$, Kaposi's sarcoma $^{32}$, osteoporosis ${ }^{33}$ and sepsis ${ }^{34}$. In addition, IL-6 plays an active role in reproduction process and $\operatorname{aging}^{35,36}$.

These observations have attracted strong interest in both understanding the functional mechanisms controlled by IL-6 and also developing antagonists and agonists as potential therapeutic agents for the treatment of IL-6-associated diseases.

\section{IL-6 in Wound Healing and Keloid}

Many studies have shown that cytokines particularly IL-6 play important roles in the pathogenesis of fibroproliferative lesions that produce collagen. IL- 6 produced by fibroblasts has been linked to the pathogenesis of fibrosis associated with rheumatoid arthritis, progressive scleroderma, and pulmonary interstitial fibrosis ${ }^{37-40}$ as well as abnormal wound healing lesions such as keloid. Increased IL- 6 gene expression and IL- 6 production in keloid patients has been reported, suggesting an altered increased autocrine regulation of IL- 6 by keloid fibroblasts that signifies a central role for this cytokine in the pathogenesis of keloid lesions ${ }^{41}$.
Moreover, the formation of keloid is associated with accumulation of extracellular matrix (ECM) components mainly of collagen ${ }^{42,43}$ and fibronectin ${ }^{44}$. Keloid fibroblasts have been shown to exhibit as much as four-fold increase in the level of fibronectin biosynthesis as compared to normal fibroblasts ${ }^{45,46}$.

Previous studies have shown that cytokines can alter fibroblast proliferation, synthesis of ECM components, as well as other functions that may regulate pathogenesis of autoimmune fibrotic diseases and keloid as well ${ }^{47-49}$. Interferon (IFN)- $\gamma$ regulates IL-6 secretion from fibroblasts by stimulating the expression of MHC class II and CD $40^{50,51}$. IFN- $\gamma$ has been also reported to increase protein production, inhibit DNA synthesis, and increase IL-6 expression in normal dermal fibroblasts $^{52}$. The production of IFN- $\alpha$, IFN- $\gamma$, and tumor necrosis factor (TNF)- $\beta$ are markedly depressed in keloid patients compared to normal controls $^{49}$. However, IL-1 and IL-2 production is not significantly different between the two groups. In contrast, keloid patients produce greater amounts of IL-6, INF- $\beta$ and TNF- $\alpha$.

Among the cytokines, transforming growth factor (TGF)- $\beta 1$ has a potent fibrogenic activity ${ }^{53.54}$. The expression of TGF- $\beta 1$ is reduced in carbon tetrachloride-induced liver fibrosis and at the wound site in transgenic IL-6 deficient mice compared with wild type mice ${ }^{55}$. Addition of TGF- $\beta 1$ or IL-6 to gingival fibroblasts promotes an increase in type I collagen and a decrease in matrix metalloproteinase (MMP)-1 and MMP-2 expression ${ }^{56}$. Taken together, IL-6 may also induce collagen deposition by induction of TGF- $\beta 1$ gene expression. Increased expression of IL-6 in normal rat skin induces epidermal proliferation and inflammation ${ }^{57}$. TGF- $\beta 1$ can promote re-epithelization of skin wounds in rats $^{54}$ and also induce epithelial cell migration and proliferation $^{58}$. In IL-6 deficient mice, lack of the IL-6 gene may delay re-epithelization through TGF- $\beta 1$. Furtheremore, mRNA and secreted protein levels of pro-MMP-1 and MMP-3 are elevated in the supernatants from normal skin fibroblasts after treatment with IL-6, whereas no changes are observed in hypertrophic scar fibroblasts treated with IL-6 ${ }^{59}$. This suggested that suppression of 
MMPs may play a role in the excessive accumulation of collagen formed in hypertrophic scars. Other studies find that IL-6 could markedly increase ECM elements such as MMP-1 and tissue inhibitor of metalloproteinase (TIMP)-1 expression at mRNA level and pro-MMP-1 at protein level ${ }^{60}$ as well as collagen synthesis ${ }^{61,42}$. In conformity with these results, we have also found that IL-6 peptide induces collagen synthesis in human fibroblast cultures in vitro $^{12,62}$. Collectively, these findings suggest that altered levels of immunoregulatory cytokines particularly IL- 6 and its receptor IL- 6 R $\alpha$ may play a significant role in the net increase in collagen synthesis which characterizes keloid formation.

In view of the integral role of inflammation and cytokines in the healing response, it is conceivable to assume that they play a major part in the pathogenesis of abnormal wound healing particularly keloid. TNF- $\alpha$ is a potent pro-inflammatory cytokine involved in activation of signaling events and transcriptional programs including NF-kappaB. On the other hand, IL-6 signaling pathway is considered as a target of NF-kappaB. The difference in NFkappaB and its related genes expression and DNA binding activity between keloid and normal skin fibroblasts has been examined using specific cDNA microarray $^{63}$. NF-kappaB binding activity has been assessed in the presence and absence of TNF- $\alpha$. Overall, TNF- $\alpha$ upregulates $15 \%$ of NF-kappaB signal pathway related genes in keloid fibroblast compared to normal skin. At the protein level, keloid fibroblasts and tissues show higher basal levels of TNF receptor-associated factors TRAF1 and TRAF $2 /$ TNF- $\alpha$ complex, as well as inhibitor of apoptosis (c-IAP-1) and NF-kappaB. Also, keloid fibroblasts show a constitutive increase in NF-kappaB binding activity in comparison to normal skin both with and without TNF- $\alpha$ treatment. It is suggested that NFkappaB and its targeted genes, especially the antiapoptotic genes, may play a role in keloid pathogenesis, and targeting NF-kappaB may help in developing therapeutic interventions for the treatment of keloid ${ }^{63}$.

In skin wound healing, IL-6 mRNA and protein are detected in neutrophils, macrophages, and fibroblasts in the wound $\operatorname{sites}^{64}$. In streptozotocin induced diabetic mice, IL-6 levels in wound fluids correlate with wound-healing rates $^{65}$ and the exogenous IL-6 administration reverses impaired wound healing in immunosuppressed mice by glucocorticoid $^{66}$, suggesting the potential involvement of IL-6 in skin wound healing. Furthermore, IL-6 is shown to induce the proliferation of fibroblasts ${ }^{67}$ and indirectly induce keratinocyte migration possibly through a soluble fibroblast-derived factor and rapid and sustained phosphorylation of STAT3 protein $^{68}$ thus can efficiently influence wound healing.

It has been reported that transgenic IL-6 deficient mice exhibit impairment in skin wound healing in parallel with a reduced activation of a transcription factor, activated protein-1 (AP-1), at the wound site ${ }^{69}$. Also a reduction in leukocyte infiltration, reepithelialization, angiogenesis, and collagen deposition at wound sites have been observed in transgenic IL-6 deficient mice compared with wild type mice ${ }^{70}$. Finally, the administration of a neutralizing anti-IL-6 monoclonal antibody significantly delays wound closure in wild type mice. It should be noted that the present effects on wound healing process are observed under conditions of inhibiting steady-state IL-6 levels required for normal cellular biological function. A recent study also reports modulation of $\alpha$-smooth muscle actin $(\alpha$ SMA) expression by recombinant mouse IL-6 (rmIL6) peptide in the dermal fibroblasts from transgenic IL-6 deficient mice ${ }^{71}$. In these fibroblasts, rmIL-6 peptide induces $\alpha$-SMA, apparently transcriptionally regulated depending on JAK1 kinase, thus implicating an important role for IL-6 in pathologies associated with myofibroblast deregulation such as chronic wounds or contractures from burn injury. Further evidences demonstrate that IL-6 can induce collagen production and/or procollagen gene expression in several types of cells including dermal fibroblasts $^{61,62}$. In fetal wound healing which is characterized by minimal inflammation and a scarless repair, less IL-6 protein and mRNA are produced by fetal fibroblasts than adult fibroblasts and IL- 6 administration to fetal wounds results in scar formation ${ }^{72}$. Thus, IL-6 deficiency can directly reduce collagen deposition in wound sites. These observations suggest that IL-6 has pivotal roles in 
wound healing, perhaps by regulating leukocyte infiltration and collagen deposition.

The formation of granulation tissue which is associated with neovascularization is another phase of wound healing. IL-6 is implicated in angiogenesis by in vitro evidence of inducing proliferation of brain microvascular endothelial cells and formation of tube-like structures $^{73}$ and also by induction of vascular endothelial growth factor (VEGF) production $^{74}$. Additionally, VEGF gene expression is reduced at wound site of IL-6 deficient mice compared to wild type mice ${ }^{69}$. These observations suggest that IL-6 may also induce angiogenesis by induction of VEGF production in the skin wound healing.

Additional studies demonstrate increased expression of the IL-6 gene in fibroblasts isolated from patients with keloids when compared with control fibroblasts using the ribonuclease protection assay $^{41}$. Subsequent detection of increased levels of IL-6 secretion by keloid fibroblasts was also demonstrated under unstimulated and stimulated conditions using serum and IFN- $\gamma$. The results suggest that IL-6 may play a significant role in the pathogenesis of keloid.

The genetic basis of keloid formation has been studied by genome-wide linkage analyses ${ }^{75}$. The results have suggested the presence of susceptibility loci on chromosomal regions $2 \mathrm{q} 23$ and $7 \mathrm{p} 11$ in a Japanese family and an African-American family, respectively. The observed locus heterogeneity may well reflect the phenotypic heterogeneity and spectrum of severity of this disease ${ }^{76}$. It is noteworthy that the gene for fibroblast activation protein alpha (FAP), a putative cell surface-bound serine protease expressed in cancer stroma and wound healing, maps to chromosome band $2 \mathrm{q} 23^{77}$ and the gene for IL- 6 is located at chromosome $7 \mathrm{p} 21$ in humans ${ }^{78}$. Whether these chromosomal region concurrences reflect any etiologic or mechanistic relationship remains to be uncovered.

The latent cytoplasmic transcription factor, STAT 3 , is rapidly activated in response to various cytokines especially IL-6, and growth factors. The possible role of STAT3 in keloid scar pathogenesis has been studied by examining skin tissue and

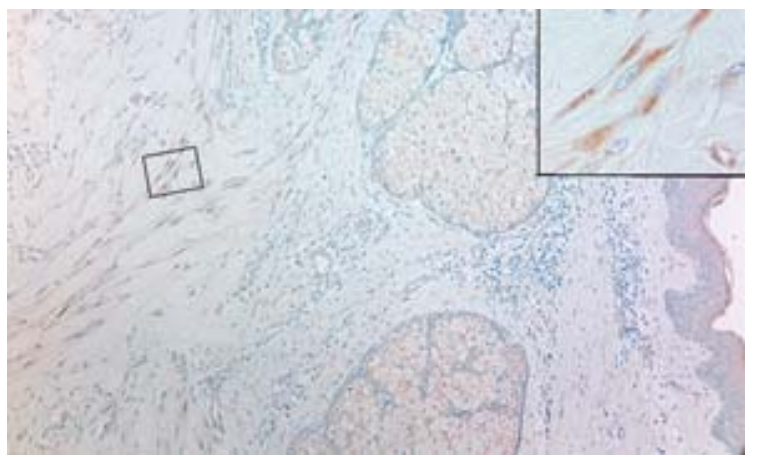

Fig. 4 Immunoperoxidase staining for IL-6 in parrafin section of a keloid lesion shows moderate to strong staining for IL-6 in keloid fibroblasts as opposed to negative reaction in normal appearing fibroblasts located at immediately sub-epidermis. Original magnification $\times 40$.

Inset: higher magnification of the squared areas $(\times 200)$.

cultured fibroblasts from keloid patients ${ }^{79}$. Based on the results obtained, enhanced expression and phosphorylation of STAT3 are observed in keloid tissue and in cultured keloid fibroblasts in vitro. Increased activation of JAK2 is detected in keloid fibroblasts, and suppression of JAK2 by its inhibitor has repressed STAT3 phosphorylation. Inhibition of STAT3 expression and phosphorylation by short interfering RNA or Cucurbitacin I has resulted in the loss of collagen production, impaired proliferation and delayed cell migration in keloid fibroblasts. It has been suggested that inhibitors of STAT3 may be useful therapeutic strategies for the prospective treatment of keloid.

In a previous study using cDNA microarray global gene expression analysis and further corroborations, we have identified a high expression of IL- 6 mRNA and protein in keloid fibroblasts as compared to nonlesional dermal fibroblasts (Fig. 4) ${ }^{12}$. We have further predicted the involvement of IL- 6 and its signaling pathway in keloid pathogenesis using the Pathway Assist software (Strategene, La Jolla, CA) that allows the user to explore gene interaction networks represented in the ResNet database; a comprehensive database of molecular networks applied to the whole PubMed database (Fig. 5) ${ }^{80}$. Subsequently, we have conducted a comprehensive study and have confirmed that the key elements of 


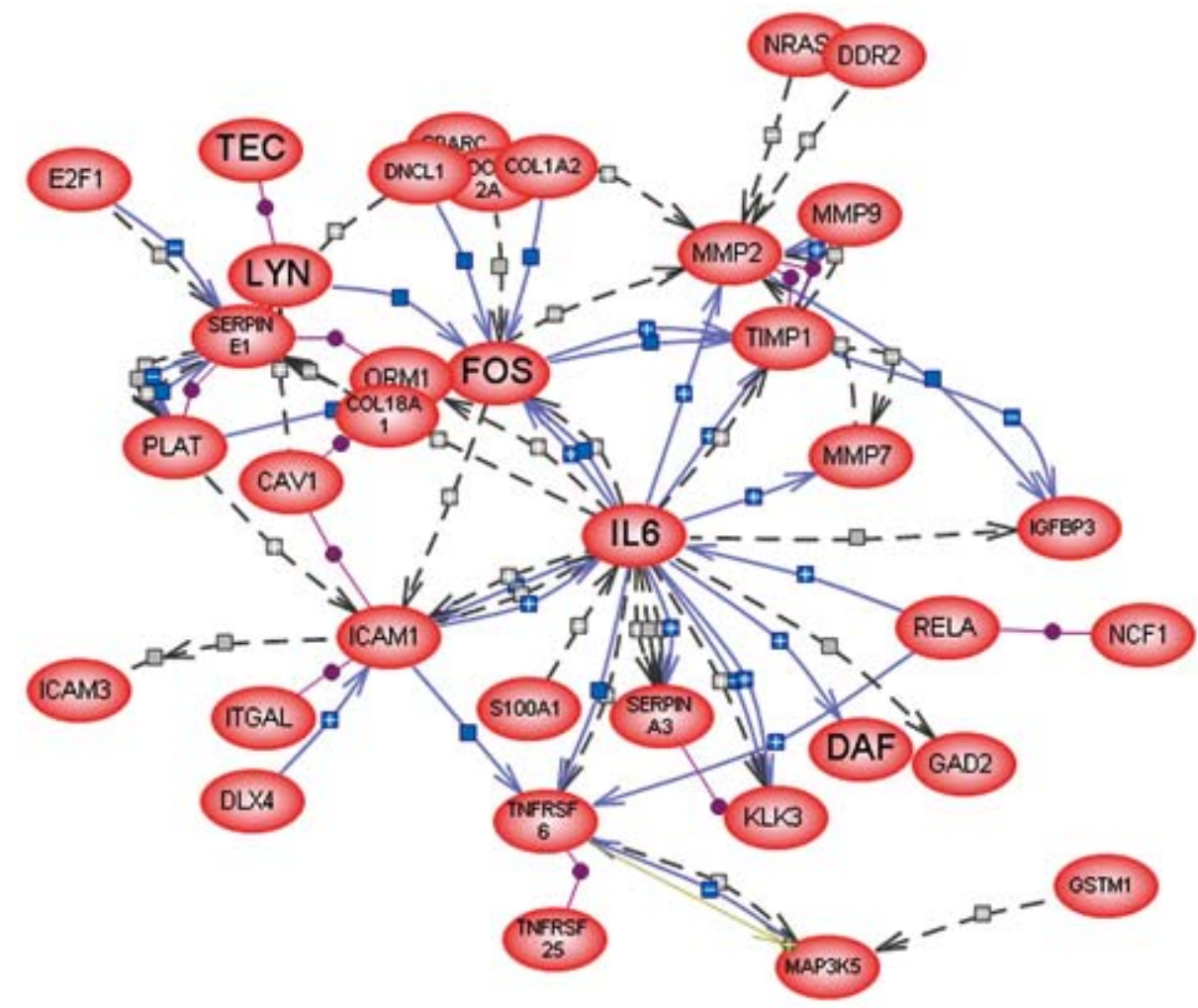

Fig. 5 Functional associations among differentially expressed genes in keloid fibroblasts. An original graphical network represented by the Pathway Assist software predicts the involvement of IL-6 cytokine in keloid pathogenesis. Squares marked with “+” or "-" denotes positive or negative effect on the gene in the direction of arrows. The upregulation of IL- 6 leads to the upregulation of several genes that promote cell proliferation or extracellular matrix production or inhibit apoptosis in parallel with downregulation of several genes that promote apoptosis or matrix degradation or inhibit cell proliferation.

the IL-6 signaling pathway, IL-6 and its receptor IL-6 $\mathrm{R} \alpha$ and gp130 (IL-6R $\beta$ ) together with a number of downstream targets including JAK1, STAT3, RAF1 and ELK1 are upregulated at mRNA and protein levels in keloid fibroblasts compared to normal fibroblasts $^{62}$. Importantly, we and others have confirmed co-expressions of IL-6 and its receptors IL-6R $\alpha$ and gp130 in keloid fibroblasts and tissues ${ }^{12,41,62}$. These findings strongly suggest the existence and activation of an autocrine IL-6 loop. Taken together, we have speculated that the upregulation of IL-6 gene may have conferred a positive effect toward keloid formation through its downstream targets in the IL-6 signaling pathway such as JAK/ STAT3 or MAPK/ERK or both leading to the induction of fibroblastic cell proliferation and matrix synthesis. In addition, the RAF1 isoform acts as the upstream kinase linking RAS activation to the
MEK/ERK module and the RAF kinases transmit signals that induce cell proliferation, differentiation, and survival. The requirement of RAF1 for normal wound healing in vivo and for the migration of kerantinocytes and fibroblasts in vitro has been recently shown ${ }^{81}$. As schematically depicted in Figure 6, injury to the skin of genetically predisposed individuals as a stimulus provokes an autocrine IL-6 activation loop in fibroblasts that stimulates JAK/STAT3 pathway (persistent STAT3 activation). This may be through the gain-of-function mutations that render a responsible factor constitutively active to mediate STAT3 activation via the induction of an autocrine IL- 6 activation loop. As a result, fibroblast cell proliferation and collagen synthesis persist in a slow and repetitive manner leading to the formation of keloid. 


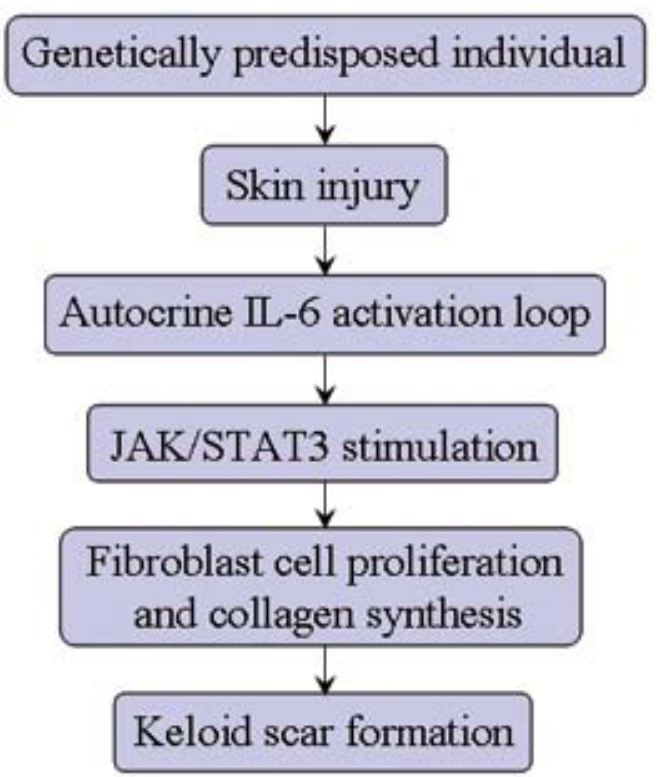

Fig. 6 Proposed model of IL-6 signaling in keloid development. Injury to the skin of genetically predisposed individuals as a stimulus provokes an autocrine IL-6 activation loop in fibroblasts that stimulates JAK/STAT3 pathway (persistent STAT3 activation). This may be through the gain-offunction mutations that render a responsible factor constitutively active to mediate STAT3 activation through the induction of an autocrine IL-6 activation loop. As a result, fibroblast cell proliferation and collagen synthesis persist in a slow and repetitive manner leading to the formation of keloid.

\section{Inhibitors of IL-6 Signaling Pathway}

Inhibition of IL-6 affects the biological activity of the protein and result in the interference of cell signaling transduction and cell cycle progression. The elevated level of IL-6 in keloid tissue than the corresponding normal tissue suggests a greater dependence on this cytokine by keloid for its function. Hence, reduction in the IL- 6 level may be more deleterious to keloid tissue than normal tissue. In other words, selective inhibition of keloid function by targeting a common molecule required for signal transduction of multiple growth stimulators may provide an effective approach to treat keloid or prevent its recurrences. Accordingly, inhibition of the signal transduction pathway for IL-6 mediated inflammation appears to be a key approach. This may be accomplished through direct inhibition of the signal transduction pathway utilizing a variety of resources such as small inhibitory molecules or antibodies to IL-6, IL-6 receptor, gp130 protein, JAK/ STAT and MAPK/ERK transcription factors, and other molecules involved in these cascades. In addition, other inhibitory challenges may include IL6 antisense oligonucleotide, partial peptides of IL- 6 or IL-6 receptor, and altered IL-6 peptide. Blocking IL-6 actions by use of a humanized antibody, tocilizumab, which targets the IL-6 receptor, has been proven to be therapeutically effective for several inflammatory diseases such as rheumatoid arthritis, systemic juvenile idiopathic arthritis, Castleman disease and Crohn's disease ${ }^{82}$. It is likely that these strategies may prove useful in keloid treatment as well, particularly the multiple keloid type.

Indirect inhibition of IL-6 mediated inflammation may be achieved by several existing pharmaceutical compounds including statins, bisphosphonates and polyphenolic drugs. These compounds can interfere with the signaling pathway for IL-6 mediated inflammation ${ }^{8384}$. Statin and bisphosphonate compounds inhibit the pathway of converting mevalonate to cholestrol and deplete isoprenoids which reduces the induction of IL-6 by activated monocytes ${ }^{858.86}$.

On the other hand, polyphenolic compounds can inhibit several pathways of signal transduction for IL-6 mediated inflammation including activation of tyrosine kinase, NF-kappaB and IKK comples ${ }^{87}$. Alternatively, a combination of these compounds may show superior effect for the therapy or prevention of keloid. Finally, the state-of-art molecular technology provides further grounds for the development of small molecule peptides, small inhibitory RNAs (sRNAs) or micro-RNAs targeting the genes in the IL-6 signaling pathway for therapeutic evaluations in keloid.

As IL-6 plays an important role in controlling the immune system, interception of the IL- 6 signaling pathway may be considered as an immunosuppressive challenge encompassing the possibility of adverse effects and thus requiring precautionary measures. In general, these may include predisposing patients to opportunistic 
infections, hypertension, hyperglycemia, dyslipidemia, and liver and kidney injuries. However, lowering and maintaining the IL-6 level at its steadystate level should not theoretically cause a major adverse effect. Other important concerns that should be taken into account include development of allergic reactions to the drug, or production of neutralizing antibodies against the drug, making it ineffective.

\section{Future Perspectives}

The results of the existing studies on the role of IL-6 in keloid pathogenesis are of highly important clinical significance. It is possible that deregulation of the IL-6 signal pathway might represent a common molecular mechanism that contribute to the pathogenesis of keloid. From a therapeutic point of view, the appreciation of dysfunction of IL-6 signaling as the underlying molecular mechanism of keloid immediately suggests that specific stabilization of IL-6 activity would have a potential therapeutic impact on keloid. This may be achieved by inhibition of IL- 6 or its receptors, IL-6R $\alpha$ or IL- 6 $\mathrm{R} \beta$ (gp130), or inhibiting targets downstream of the IL-6 signaling pathway or other pathways targeting IL-6 such as NF-kappaB or IKK. Fortunately, several IL-6 blocking agents including a humanized anti-IL-6 receptor antibody has been developed and successfully applied in clinical trials for the treatment of several inflammatory diseases ${ }^{82}$. As keloid is also considered an IL-6 mediated inflammatory lesion, it is likely that such IL-6 blocking strategies work well in keloid patients too. In this context, patients with multiple keloids would probably be the candidate. However, this speculation awaits future in-depth exploration of efficacy and safety of such approach for clinical application in keloid.

Given the important roles of IL-6 signaling pathway in wound healing and the severe consequences associated with disruption of IL-6 signals, it is conceivable that IL- 6 may be subjected to additional regulation and might have a target spectrum much broader than the spectrum we know about at present. To further elucidate the involvement of IL-6 in keloid pathogenesis, it would be important to identify additional linkages as well as other novel IL-6 effectors. At present, the lack of experimental animal models has vastly hampered in vivo studies on keloid development. Future studies may be focused on the identification of gain-offunction mutations that render an existing or a “novel” JAK/STAT3 stimulator constitutively active to persistently stimulate STAT3 activation via the induction of an autocrine IL-6 activation loop. These experiments may be performed in vitro using human and rodent fibroblast cell lines. Subsequently the development of transgenic mice carrying such mutations may prove useful as an animal model of keloid.

Taken together, these efforts would certainly broaden our knowledge of IL-6 biology and potentially expand the therapeutic spectrum of IL- 6 blocking strategies.

\section{References}

1. Craig RD: Collagen biosynthesis in normal human skin, normal and hypertrophic scar and keloid. Eur J Clin Invest 1975; 5: 69-74.

2. Al-Attar A, Mess S, Thomassen JM, Kauffman CL, Davison SP: Keloid pathogenesis and treatment. Plast Reconstr Surg 2006; 117: 286-300.

3. Yagi KI, Dafalla AA, Osman AA: Does an immune reaction to sebum in wounds cause keloid scars? Beneficial effect of desensitization. Br J Plast Surg 1979; 32: 223-225.

4. Fong EP, Bay BH: Keloids: The sebum hypothesis revisited. Med Hypotheses 2002; 58: 264-269.

5. Yu H, Bock O, Bayat A, Ferguson MW, Mrowietz U: Decreased expression of inhibitory SMAD6 and SMAD7 in keloid scarring. J Plast Reconstr Aesthet Surg 2006; 59: 221-229.

6. Kishimoto $\mathrm{T}$, Hirano $\mathrm{T}$ : Molecular regulation of $\mathrm{B}$ lymphocyte response. Annu Rev Immunol 1988; 6: 485-512.

7. Knupfer H, Preiss R: Significance of interleukin-6 (IL6) in breast cancer. Breast Cancer Res Treat 2006; Aug 23 [Epub ahead of print].

8. Kelly AP: Keloids. Dermatol Clin 1988; 6: 413-424.

9. Berman B, Duncan MR: Short-term keloid treatment in vivo with human interferon alpha- $2 \mathrm{~b}$ results in a selective and persistent normalization of keloidal fibroblast collagen, glycosaminoglycan, and collagenase production in vitro. J Am Acad Dermatol 1989; 21: 694-702.

10. Panabiere-Castaings $\mathrm{MH}$ : Retinoic acid in the treatment of keloids. J Dermatol Surg Oncol 1988; 14: 1275-1276.

11. Daly TJ, Weston WL: Retinoid effects on fibroblast proliferation and collagen synthesis in vitro and on 
fibrotic disease in vivo. J Am Acad Dermatol 1986; 15: 900-902.

12. Tosa M, Ghazizadeh M, Shimizu H, Hirai T, Hyakusoku H, Kawanami O: Global gene expression analysis of keloid fibroblasts in response to electron beam irradiation reveals the involvement of interleukin-6 pathway. J Invest Dermatol 2005; 124: 704-713.

13. Ogawa R, Mitsuhashi K, Hyakusoku H, Miyashita T: Postoperative electron-beam irradiation therapy for keloids and hypertrophic scars:retrospective study of 147 cases followed for more than 18 months. Plast Reconstr Surg 2003; 111: 547-553.

14. Giugliano G, Pasquali D, Notaro A, et al.: Verapamil inhibits interleukin-6 and vascular endothelial growth factor production in primary cultures of keloid fibroblasts. Br J Plast Surg 2003; 56: 804-809.

15. Hirano T, Taga T, Nakano N, et al.: Purification to homogeneity and characterization of human B-cell differentiation factor (BCDF or BSFp-2). Proc Natl Acad Sci USA 1985; 82: 5490-5494.

16. Van Damme J, Cayphas S, Van Snick J, et al: Purification and characterization of human fibroblast-derived hybridoma growth factor identical to T-cell-derived B-cell stimulatory factor-2 (interleukin-6). Eur J Biochem 1987; 168: 543-550.

17. May LT, Shaw JE, Khanna AK, Zabriskie JB, Sehgal PB: Marked cell type-specific differences in glycosylation of human interleukin-6. Cytokine 1991; 3: 204-211.

18. May LT, Santhanam U, Sehgal PB: On the multimeric nature of natural human interleukin-6. J Biol Chem 1991; 266: 9950-9955.

19. Kishimoto T, Taga T, Akira S: Cytokine signal transduction. Cell 1994; 76: 253-262.

20. Ihle JN: Cytokine receptor signaling. Nature 1995; 377: 591-594.

21. Novick D, Engelmann H, Wallach D, Rubinstein M: Soluble cytokine receptors are present in normal human urine. J Exp Med 1989; 170: 1409-1414.

22. De Benedetti F, Massa M, Pignatti P, Albani S, Novick D, Martini A: Serum soluble interleukin 6 (IL6) receptor and IL-6/soluble IL-6 receptor complex in systemic juvenile rheumatoid arthritis. J Clin Invest 1994; 93: 2114-2119.

23. Narazaki M, Yasukawa K, Saito T, et al.: Soluble forms of the interleukin-6 signal-transducing receptor component gp130 in human serum possessing a potential to inhibit signals through membrane-anchored gp130. Blood 1993; 82: 11201126.

24. Gaillard JP, Liautard J, Mani JC, Femandez Suarez $\mathrm{JM}$, Klein B, Brochier J: Identification of a novel antigenic structure of the human receptor for interleukin-6 involved in the interaction with the glycoprotein 130 chain. J lmmunol 1996; 89: 135-141.

25. Squarize CH, Castilho RM, Sriuranpong V, Pinto DS Jr, Gutkind JS: Molecular cross-talk between the NFkappaB and STAT3 signaling pathways in head and neck squamous cell carcinoma. Neoplasia 2006; 8: 733-746.

26. Perkins ND: Integrating cell-signalling pathways with NF-kappaB and IKK function. Nat Rev Mol Cell Biol 2007; 8: 49-62.

27. Hirano T, Matsuda T, Turner M, et al.: Excessive production of interleukin 6/B cell stimulatory factor2 in rheumatoid arthritis. Eur J Immunol 1988; 18: 1797-1801.

28. Kawano M, Hirano T, Matsuda T, et al.: Autocrine generation and requirement of BSF-2/IL-6 for human multiple myelomas. Nature 1988; 332: 83-85.

29. Nakajima $K$, Martinez-Maza O, Hirano $T$, et al: Induction of IL-6 (B cell stimulatory factor $2 / \mathrm{IFN} / \mathrm{p} 2$ ) production by HIV. J lmmunol 1989; 142: 144-147.

30. Horii Y, Muraguchi A, Iwano M, et al.: Involvement of interleukin-6 in mesangial proliferative glomerulonephritis. J Immunol 1989; 143: 3949-3955.

31. Yoshizaki K, Matsuda T, Nishimoto N, et al.: Pathogenic significance of interleukin-6 (IL-6/BSF-2) in Castleman's disease. Blood 1989; 74: 1360-1367.

32. Miles SA, Rezai AR, Salazar-Gonzales JF, et al.: AIDS Kaposi sarcoma-derived cells produce and respond to interleu-kin 6. Proc Natl Acad Sci USA 1990; 87: 4068-4072.

33. Jilka RL, Hangoc G, Girasole G, et al.: Increased osteoclast development after estrogen loss: Mediation by interleukin-6. Science 1992; 257: 88-91.

34. Waage A, Brandtzaeg P, Halstensen A, Kierulf P, Espevik T: The complex pattern of cytokines in serum from patients with meningococcal septic shock. Association between interleukin-6, interleukin1 and fatal outcome. J Exp Med 1989; 169: 333-338.

35. Makkar G, Ng EH, Yeung WS, Ho PC: Reduced expression of interleukin-11 and interleukin- 6 in the periimplantation endometrium of excessive ovarian responders during in vitro fertilization treatment. J Clin Endocrinol Metab 2006; 91: 3181-3188.

36. Maggio M, Guralnik JM, Longo DL, Ferrucci L: Interleukin-6 in aging and chronic disease: a magnificent pathway. J Gerontol A Biol Sci Med Sci 2006; 61: 575-584.

37. Shahar I, Fireman E, Topilsky M, et al.: Effect of IL-6 on alveolar fibroblast proliferation in intestinal lung disease. Clin Immunol Immunopathol 1996; 79: 244251.

38. Tan PL, Farmiloe S, Yeoman S, Watson JD: Expression of the interleukin 6 gene in rheumatoid synovial fibroblasts. J Rheumatol 1990; 17: 1608-1612.

39. Feghali CA, Bost KL, Boulware DW, Levy LS: Control of IL-6 expression and response in fibroblasts from patients with systemic sclerosis. Autoimmunity 1994; 17: 304-318.

40. Gurram M, Pahwa S, Feieri M: Augmented interleukin-6 serection in collagen-stimulated peripheral blood mononuclear cells from patients with systemic sclerosis. Ann Allergy 1994; 73: 493496.

41. Xue H, McCauley RL, Zhang W: Elevated interleukin-6 expression in keloid fibroblasts. J Surg Res 2000; 89: 74-77.

42. Friedman DW, Boyd CD, Mackenzie JW, Norton P, Olson RM, Deak SB: Regulation of collagen gene expression in keloids and hypertrophic scars. J Surg Res 1993; 55: 214-222.

43. Fujiwara M, Muragaki Y, Ooshima A: Keloid-derived fibroblasts show increased secretion of factors involved in collagen turnover and depend on matrix metalloproteinase for migration. Brit J Dermatol 2005; 153: 295-300.

44. Kischer CW, Hendrix MJ: Fibronectin (FN) in 
hypertrophic scars and keloids. Cell Tissue Res 1983; 231: 29-37.

45. Babu M, Diegelmann R, Oliver N: Fibronectin is overproduced by keloid fibroblasts during abnormal wound healing. Mol Cell Biol 1989; 9: 1642-1650.

46. Oliver N, Babu M, Diegelmann R: Fibronectin gene transcription is enhanced in abnormal wound healing. J Invest Dermatol 1992; 99: 579-586.

47. Ferrarini M, Steen V, Medsger TA Jr, Whiteside TL: Functional and phenotypic analysis of $\mathrm{T}$ lymphocytes cloned from the skin of patients with systemic sclerosis. Clin Exp Immunol 1990; 79: 346352.

48. Elias JA, Freundlich B, Adans S, Rosenbloom J: Cytokine networks in the regulation of inflammation and fibrosis in the lung. Chest 1990; 97: 1439-1445.

49. McCauley RL, Chopra V, Li YY, Herndon DN, Robson MC: Altered cytokine production in black patients with keloids. J Clin Immunol 1992; 12: 300308.

50. Mourad W, Mehindate K, Schall TJ, McColl SR: Engagement of major histocompatibility complex class II molecules by superantigen induces inflammatory cytokine gene expression in human rheumatoid fibroblast-like synoviocytes. J Exp Med 1992; 175: 613-616.

51. Yellin MJ, Winikoff S, Fortune SM, et al.: Ligation of CD40 on fibroblasts induces CD54 (ICAM-1) and CD 106 (VCAM-1) up-regulation and IL-6 production and proliferation. J Leukoc Biol 1995; 58: 209-216.

52. Maruyama K, Zhang JZ, Nihei Y, Ono I, Kaneko F: Regulatory effects of gamma-interferon on IL-6 and IL-8 secretion by cultured human keratinocytes and dernal fibroblasts. J Dermatol 1995; 22: 901-906.

53. Quaglino D Jr, Nanney LB, Ditesheim JA, Davidson JM: Transforming growth factor-beta stimulates wound healing and modulates extracellular matrix gene expression in pig skin: incisional wound model. J Invest Dermatol 1991; 97: 34-42.

54. Mustoe TA, Pierce GF, Thomason A, Gramates P, Sporn MB, Deuel TF: Accelerated healing of incisional wounds in rats induced by transforming growth factor-beta. Science 1987; 237: 1333-1336.

55. Natsume M, Tsuji H, Harada A, et al: Attenuated liver fibrosis and depressed serum albumin levels in carbon tetrachloride-treated IL-6-deficient mice. J Leukoc Biol 1999; 66: 601-608.

56. Martelli-Junior H, Cotrim P, Graner E, Sauk JJ, Coletta RD: Effect of transforming growth factorbeta1, interleukin-6, and interferon-gamma on the expression of type I collagen, heat shock protein 47 , matrix metalloproteinase (MMP)-1 and MMP-2 by fibroblasts from normal gingiva and hereditary gingival fibromatosis. J Periodontol 2003; 74: 296-306.

57. Sawamura D, Meng X, Ina S, et al.: Induction of keratinocyte proliferation and lymphocytic infiltration by in vivo introduction of the IL- 6 gene into keratinocytes and possibility of keratinocyte gene therapy for inflammatory skin diseases using IL-6 mutant genes. J Immunol 1998; 161: 5633-5639.

58. Hebda PA: Stimulatory effects of transforming growth factor-beta and epidermal growth factor on epidermal cell outgrowth from porcine skin explant cultures. J Invest Dermatol 1988; 91: 440-445.

59. Dasu MR, Hawkins HK, Barrow RE, Xue H, Herndon
DN: Gene expression profiles from hypertrophic scar fibroblasts before and after IL-6 stimulation. J Pathol 2004; 202: 476-485.

60. Dasu MR, Barrow RE, Spies M, Herndon DN: Matrix metalloproteinase expression in cytokine stimulated human dermal fibroblasts. Burns 2003; 29: 527-531.

61. Duncan MR, Berman B: Stimulation of collagen and glycosaminoglycan production in cultured human adult dermal fibroblasts by recombinant human interleukin 6. J Invest Dermatol 1991; 97: 686-692.

62. Ghazizadeh M, Tosa M, Shimizu H, Hyakusoku H, Kawanami O: Functional implications of the IL-6 signaling pathway in keloid pathogenesis. J Invest Dermatol 2007; 127: 98-105.

63. Messadi DV, Doung HS, Zhang Q, et al.: Activation of NFkappaB signal pathways in keloid fibroblasts. Arch Dermatol Res 2004; 296: 125-133.

64. Sato Y, Ohshima T: The expression of mRNA of proinflammatory cytokines during skin wound healing in mice: a preliminary study for forensic wound age estimation (II). Int J Legal Med 2000; 113: 140-145.

65. Fahey TJ III, Sadaty A, Jones WG II, Barber A, Smoller B, Shires GT: Diabetes impairs the late inflammatory response to wound healing. J Surg Res 1991; 50: 308-313.

66. Gallucci RM, Sugawara T, Yucesoy B, et al.: Interleukin- 6 treatment augments cutaneous wound healing in immunosuppressed mice. J Interferon Cytokine Res 2001; 21: 603-609.

67. Mihara M, Moriyama Y, Kishimoto T, Ohsugi Y: Interleukin-6 (IL-6) induces the proliferation of synovial fibroblastic cells in the presence of soluble IL-6 receptor. Br J Rheumatol 1995; 34: 321-325.

68. Gallucci RM, Sloan DK, Heck JM, Murray AR, O’Dell SJ: Interleukin 6 indirectly induces keratinocyte migration. J Invest Dermatol 2004; 122: 764-772.

69. Gallucci RM, Simeonova PP, Matheson JM, et al. Impaired cutaneous wound healing in interleukin-6deficient and immunosuppressed mice. FASEB J 2000; 14: 2525-2531.

70. Lin ZQ, Kondo T, Ishida Y, Takayasu T, Mukaida N: Essential involvement of IL-6 in the skin woundhealing process as evidenced by delayed wound healing in IL-6-deficient mice. J Leukoc Biol 2003; 73: 713-721.

71. Gallucci RM, Lee EG, Tomasek JJ: IL-6 modulates alpha-smooth muscle actin expression in dermal fibroblasts from IL-6-deficient mice. J Invest Dermatol 2006; 126: 561-568.

72. Liechty KW, Adzick NS, Crombleholme TM: Diminished interleukin 6 (IL-6) production during scarless human fetal wound repair. Cytokine 2000; 12: $671-676$.

73. Fee D, Grzybicki D, Dobbs M, et al.: Interleukin 6 promotes vasculogenesis of murine brain microvessel endothelial cells. Cytokine 2000; 12: 655665.

74. Cohen T, Nahari D, Cerem LW, Neufeld G, Levi BZ: Interleukin 6 induces the expression of vascular endothelial growth factor. J Biol Chem 1996; 271: 736-741.

75. Marneros AG, Norris JE, Watanabe S, Reichenberger E, Olsen BR: Genome scans provide evidence for keloid susceptibility loci on chromosomes2q23 and $7 \mathrm{p}$ 
11. J Invest Dermatol 2004; 122: 1126-1132.

76. Uitto J: IL-6 signaling pathway in keloids: a target for pharmacologic intervention? J Invest Dermatol 2007; 127: 6-8.

77. Mathew S, Scanlan MJ, Mohan Raj BK, et al.: the gene for fibroblast activation protein alpha (FAP), a putative cell surface-bound serine protease expressed in cancer stroma and wound healing, maps to chromosome band 2q23. Genomics 1995; 25: 335-337.

78. Sehgal PB, Zilberstein A, Ruggieri RM, et al.: Human chromosome 7 carries the beta 2 interferon gene. Proc Natl Acad Sci USA 1986; 83: 5219-5222.

79. Lim CP, Phan TT, Lim IJ, Cao X: Stat3 contributes to keloid pathogenesis via promoting collagen production, cell proliferation and migration. Oncogene 2006; 25: 5416-5425.

80. Yonan AL, Palmer AA, Smith KC, et al.: Bioinformatic analysis of autism positional candidate genes using biological databases and computational gene network prediction. Genes Brain Behav 2003; 2: 303-320.

81. Ehrenreiter K, Piazzolla D, Velamoor V, et al.: Raf-1 regulates Rho signaling and cell migration. J Cell Biol 2005; 168: 955-964.

82. Nishimoto N, Kishimoto T: Interleukin 6: from bench to bedside. Nat Clin Pract Rheumatol 2006; 2: 619626
83. Horiuchi M, Cui TX, Li Z, Li JM, Nakagami H, Iwai M: Fluvastatin enhances the inhibitory effects of a selective angiotensin II type 1 receptor blocker, valsartan, on vascular neointimal formation. Circulation 2003; 107: 106-112.

84. Iguchi T, Miyakawa Y, Yamamoto K, Kizaki M, Ikeda Y: Nitrogen-containing bisphosphonates induce S-phase cell cycle arrest and apoptosis of myeloma cells by activating MAPK pathway and inhibiting mevalonate pathway. Cell Signal 2003; 15: 719-727.

85. Mundy GR: Statins and their potential for osteoporosis. Bone 2001; 29: 495-497.

86. Santini D, Fratto ME, Vincenzi B, La Cesa A, Dianzani C, Tonini G: Bisphosphonate effects in cancer and inflammatory diseases: in vitro and in vivo modulation of cytokine activities. BioDrugs 2004; 18: 269-278.

87. Chen CC, Chow MP, Huang WC, Lin YC, Chang YJ: Flavonoids inhibit tumor necrosis factor-alphainduced up-regulation of intercellular adhesion molecule-1 (ICAM-1) in respiratory epithelial cells through activator protein-1 and nuclear factorkappaB : structure-activity relationships. Mol Pharmacol 2004; 66: 683-693.

(Received, December 25, 2006)

(Accepted, January 16, 2007) 